\title{
Three generations of experience and thought in microbiology and infection
}

\author{
Morris Goldner PhD
}

M Goldner. Three generations of experience and thought in microbiology and infection. Can J Infect Dis 2003;14(6): 329-335.

Views and comments were sought from Brian Lacey, who was professionally active from the 1930s to the 1970s, Alain Dublanchet, active from the 1960s to the 2000s, and Mark Pallen, active from the 1990s to 2000 and beyond. Professor Lacey was professor of microbiology at the Westminster Medical School, University of London, United Kingdom, for many years and is now retired. Docteur Dublanchet is the long time head of the laboratory of microbiology and virology at the Centre Hospitalier Intercommunal de Villeneuve-Saint-Georges in the greater Paris area. Professor Pallen is currently professor of bacterial genetics at the Medical School, University of Birmingham (United Kingdom); he is a keen enthusiast of genomic studies in the interest of molecular pathogenesis research. All three are medically qualified. Four questions were posed to each:

What was the situation like in the infectious disease field when you first started your career?

What do you feel have been the most important accomplishments with regard to problems of infectious disease during your period of activity?

What do you foresee as the vital matters that still need to be addressed for countering infectious disease?

Can infectious disease ever, practically, be eradicated and, if so, how would this be accomplished?

\section{Microbiologie et infectiologie : expérience et points de vue de trois générations}

Nous avons sollicité le point de vue de trois spécialistes en la matière sur de grands sujets. Il s'agit de Brian Lacey, professeur entre les années 1930 et 1970; d'Alain Dublanchet, médecin entre les années 1960 et 2000, et de Mark Pallen, professeur entre les années 1990 et 2000 et même au-delà. Le premier a été professeur de microbiologie à la Westminster Medical School, à l'université de Londres, au Royaume-Uni, durant de nombreuses années et il est maintenant à la retraite. Le deuxième est depuis longtemps chef du laboratoire de microbiologie et de virologie au Centre hospitalier intercommunal de Villeneuve-SaintGeorges dans la grande région parisienne. Le troisième est professeur de génétique bactérienne à la Medical School, à l'université de Birmingham, au Royaume-Uni; il est passionné de génomique, plus particulièrement en ce qui a trait à la pathogenèse moléculaire. Tous les trois sont qualifiés en médecine. Nous avons posé à chacun les quatre questions suivantes:

Comment décririez-vous la situation relativement aux maladies infectieuses au début de votre carrière?

Quelles ont été, à votre avis, les réalisations les plus importantes dans le domaine des maladies infectieuses pendant votre vie professionnelle?

Quels problèmes d'importance vitale restent encore à vaincre pour lutter contre les maladies infectieuses?

Est-il possible que, un jour, les maladies infectieuses soient pour ainsi dire éradiquées et, si oui, comment?

Key Words: Infectious disease

\section{PROFESSOR BRIAN LACEY}

$\mathrm{Q}$. What was the situation like in the infectious disease field when you first started out?

In the 1930s, when I was a medical intern, infection did not dominate the field, but you could never escape from it. Every day you saw infection. I saw people die of streptococcal and staphylococcal infections, diphtheria, tuberculosis, measles and influenza, and there was nothing you could do about it. When I was doing a house position job in neurology, I recall a young girl with pneumococcal meningitis. She had an infection in one of her sinuses that spread to the meninges, and the poor girl just died; there was nothing you could do. Trying to comfort the parents under these conditions was agonizing...

\section{Q. What do you feel have been the most important accomplishments with regard to infectious diseases during your period of activity?}

I saw a series of achievements. The first was Domagk's introduction of sulphanilamide. That was revolutionary as the first

Faculté de Médecine, Université Laval, Cité Universitaire, Quebec, Quebec, and Academic Visitor, Wellcome Unit for the History of Medicine at Oxford, Oxford, United Kingdom

Correspondence and reprints: Dr M Goldner, Faculté de Médecine, Université Laval, Cité Universitaire, Quebec, Quebec G1K 7P4

Telephone 418-656-3351, fax 418-656-7666, e-mail mcbmgo@hermes.ulaval.ca (Academic Visitor, Wellcome Unit for the History of

Medicine at Oxford, 45-47 Banbury Road, Oxford OX2 6PE, United Kingdom. Telephone 0-1865-274600, fax 0-1865-274605)

Received for publication July 29, 2003. Accepted September 29, 2003 
compound that affected streptococcal infection. We used to see a lot of impetigo - children with terribly infected faces and skin, and serious erysipelas of the arms and legs. Sulphanilamide revolutionized the treatment of these infections, but did not affect the pneumococcus. I was working in the laboratory of Dr Lionel Whitby when he and his chief technician, Bushby, introduced several new chemotherapeutic agents. They found one, sulphapyridine, and tested it in mice. A young houseman (resident) working on a medical ward asked me "Did the pathologists know anything about treating pneumococcal pneumonia?" I replied that we had a new drug, and he tried that, and the man survived. But you could not use sulphapyridine for meningitis. It would not get into the meninges or brain.

The next advance was the use of streptomycin against tuberculosis. In my early days, a person would come in for a surgical operation, and if tubercle bacilli were in their sputum, it would be necessary to postpone the operation. For gastroenterology surgery, I found tubercle bacilli in the feces of patients, and they would have tubercular enteritis. It was terrible about tuberculosis. There was almost at least one patient in every ward in the hospital, and there were sputum mugs, dozens and dozens of sputum mugs, it was horrible... So when Waksman discovered streptomycin, it altered that situation dramatically. Other agents were introduced after Waksman's streptomycin; isoniazid was one of the most prominent and valuable.

Then there were lots of whooping cough. Children were terribly ill with it. Vaccination was just starting.

The treatment of serious staphylococcal infections, especially septicemia with lung abscesses, was pathetic during the 30s. Just before the onset of the last world war, I was asked to deputize for my chief who was ill, to give advice on a patient who had a very serious septicemia. I could not provide advice because there was no agent to treat staphylococci. I suggested they might try Burroughs-Wellcome's, or some other firm's antiserum. The whole serum was injected and the patient suffered a terrible serum sensitivity reaction and died. So, antistaphylococcal antibodies were not of use against septicemia. That was about 1938, I think. Agents active against staphylococci, vancomycin and the penicillins, had not yet been developed at the time.

During the wartime, my chief in the Middle East, in Cairo, received the first batch of usable penicillin from Florey's group at Oxford, and we tested it on several wound infections with tremendous success. Unfortunately, of course, future supplies just vanished; then young men with head injuries were dying of meningitis caused by pseudomonas bacteria, which you find in water. Well, the local people were extracting the penicillin from the ampules and filling it up with coloured water. And this is what was injected into the cerebral spinal fluid. And of course, they died, as there were no compounds then against the pseudomonas.

Penicillin was of course the most amazing of the whole lot. It changed the face of infection in war wounds, absolutely. Instead of thinking of having to put fly larvae into undebrided tissue to cleanse it, the wounds healed with penicillin.

When I was working in the Middle East during the war, as a pathologist, we had a patient come in, dying of some infection. Looking at him carefully, I saw a funny little infected pimple on his leg, and we cultured his blood, and it proved to be filled with Pasteurella pestis organisms - bubonic plague. And in further examining the patient, he had a big bubo in his inguinal region, from the flea bite below. The flea bite lesion grew the same organisms. I reported the results to Cairo, to the central laboratory, and they replied "Oh no! It could not be plague. There is no plague." I said "I have really looked at this, I have tested this in a guinea pig and the guinea pig has died with septicemia. I have grown this organism from the blood of the patient who died, and from his lungs and his presumptive flea bite." We learned he had been working on the docks in Egypt and had obviously been bitten by a flea. They insisted we send the culture to an Egyptian expert, who said that it was not Pasteurella pestis. He had not done the proper tests! He had not used the sugar reactions to prove that it was pestis and he had not put it into an animal test. Eventually it was accepted that this man had died of the plague. People were alarmed in the rest of the unit, and asked "What are we going to do with all of the people in contact?" Of course, there was nothing to do, because penicillin could not touch it. What was recommended was antiplague serum, if it existed. So Cairo sent us lots of goat antiserum and we injected most of those who had been in contact. Again, one of the young men developed terrible serum sickness. I would never inject crude serum ever again into anybody. Well, the advance there was that sulphanilamide itself was quite active against the plague bacillus, and could save you if it were properly administered.

People were most interested in advancing immunization against influenza. I never experienced a devastating epidemic in the 30s comparable to that after the first world war in 1918 and 1919. With a research fellowship at the University of London set up by the Rolls Royce people for research into influenza and respiratory infections, I started to cultivate cold exudate from army people to see how you could produce an infection in a rabbit. I was still working on this when the war broke out, but was in uniform two days after the outbreak of the war... The next thing that I recall is the smallpox vaccine. I saw quite a lot of smallpox during the war. We used to examine the pox and diagnose it on microscopic evidence, because it is such a big virus that you can stain it and see it using a technique developed by a man called van Rooyen. He worked at Dalhousie University in Halifax, Canada afterwards.

It was after the war that I became interested in Bordetella pertussis. When I came back, the university administration was legally obliged to offer you a six-month job. The then dean did not like this and thought it was an imposition on his authority.

When I applied for a job, Cruikshank, who became the professor at Saint Mary's Hospital (London), said "The trouble is, no one ever takes an interest in pertussis (whooping cough); I think we should do something." And we grew the bacteria, then we began to try to make a selective medium, because at that time, the only diagnostic way was to take cough plates. They are not very good and they have lots of contaminants from the mouth and nose. The researchers at May \& Baker sent me some small samples of diaminadines that they had been using with one of their research contacts on some other problem. We found one, M\&B938 (diaminadino diphenylamine), which was absolutely splendid, and that is still the most effective agent, enabling you to use throat, nasal and pharyngeal swabs, eliminating the other organisms; with almost pure cultures. I wrote a thesis on this, and that got me a $\mathrm{MD}$ at London, with a publication.

I did a lot of studies of the colonies of Bordetella pertussis, yes, and into the antigenic structure of the organism, in terms of different media at different temperatures. To find the best 
selective medium to go with the new drug from May \& Baker, eventually we combined the best nutrient medium and the best antagonist for the contaminants. This combination was absolutely splendid!

That led to what substitutions in the media reveal indications about the antigenic structure... The biggest, most obvious antigenic change was if you substituted common salt by magnesium sulphate, the pertussis organism seemed to like the magnesium, in fact, and salts like citrate or other salts. And the changes were obviously very different. And looking at the scientific literature, other observers noticing antigenic changes had used the term 'phase variation'. But of course, what they were seeing was a 'modulation', not really a phase change. A phase change occurs in, for example, salmonella which change the structure of their flagella, and they jump from one structure to another. But that is a phase change, which lasts quite a long time. You can play about with it in one phase without it going back to another. So it was not a phase change, but obviously something else. And we had to coin a word for it, and looking at the literature again, there were masses of references at that time, in the late 50s, about antigenic changes. But no one had used the word 'modulation' directly for that phenomenon. But it seemed easily the best way to enable you to talk about modes and modulate ability, and so on. And also mutation to nonmodulate ability, as we had nonmodulatable mutants of pertussis bacteria.

Pertussis became a major interest for me, without a doubt. And the more you go into the interaction of different salts in determining the antigenic state of an organism, it becomes absolutely fascinating! There are two or three other species in the genus Bordetella, and they all react differently. Some do not act in the same way as pertussis at all, and all acted at different temperatures and at different mixtures of salt levels, all very complex...

And the significance of the modulation, to my mind, has never been fully exploited, even now. What antigenic mode is really the best immunizing agent for humans? That has never been properly tested. Either in animals or in humans. And looking at the then available pertussis vaccines, they were nearly all modulated from the wild state into a sort of laboratory, or previously called 'phase state'. Obviously, they were degenerated in some way (so-called phase 4).

I concentrated so much on Bordetella but I was also testing other aspects. How do you preserve and keep the organism in the best condition when you take swabs from children? What transport medium to best get the swabs into the laboratory? And in testing various media (semi-liquid), I found one where you put the swab into a sort of sloppy mixture that preserved the organism for days and days. But, nobody was interested in that.

\section{Q. What do you foresee as the vital matters that still need to be addressed for countering the problems of infectious disease?}

I see a number of problems at the moment. Multiple-resistant staphylococci are causing immense disease all over the place, and success will depend on developing new antibiotics that break new chemical ground. Another problem is the need for more mosquito control in relation to malaria. With all the flooding that has occurred over Europe, I think many countries are liable to have a tremendous upsurgence of mosquito replication and this is bound to lead to more malarial trans- mission. Further, there is continuing trouble with AIDS, especially in Africa.

\section{Q. Can infectious disease ever practically be eradicated and, if so, how would this be accomplished?}

There is only an example of one which comes to mind. That is smallpox, which has potentially almost been completely eradicated. By effective vaccination, in the last 40 years, smallpox has disappeared. And of course the plague is finished. I cannot ever imagine the plague arising again given the sulphonamides and lack of close contact with rats and fleas, with hygiene being a big factor. But, I do think that if there were really effective antiplasmodial vaccines, this might eradicate malaria in some parts of the world, which would be wonderful.

The problem of flu every 10 years or so on in the world is difficult to know about. The flu virus is horrible, and very flexible and unpredictable. As for the idea of eliminating it, I do not see any possibility of that. I have not seen recently a proper survey of what factors contribute to the establishment of an epidemic of flu. Christopher Andrews, you know, had different views to the Dutch microbiologists who felt they could know from weather information when a flu would be active.

What we can do, generally, is to take a fresh look at the misuse of chemical agents for environmental hygiene. What is needed is the proper design of water supplies and effective fecal disposal, so it is a matter of public health organization. That is a political problem to be solved.

The occurrence, almost out of nowhere, of unusual infections, such as bovine spongiform encephalopathy infection, is a matter of prevention; if there were a way of eradicating it when knowing it was developing in herds, then of course, you could deal with it. But, it depends once again on the farms and the slaughterhouses, and they use every bit of animal material. I cannot see prevention ever happening... For those in industry, when their income and their livelihood are at stake, they are going to find ways of short-circuiting regulations. With regard to food hygiene and other aspects of food cleanliness and hygiene, I think the establishment of a consumer inspectorate is a first step.

For persons like myself who have lived through such an exciting transformation from the whole scene, it remains very interesting indeed!

Thank you very much, Professor Lacey!

\section{DOCTEUR ALAIN DUBLANCHET}

$Q$. When you began your career in the field of infectious diseases, what was the perception or scope of this area of specialization? Can you describe how it was for you? What made you choose this particular profession?

I went into medicine to study biology and, more specifically, bacteriology. This field appealed to me because of its more 'artistic' aspects; not that I had the temperament of an artist, but rather because the fields of investigation appeared to be less structured, and more open to the individual initiative.

In the 1960s, I entered the profession with the firm conviction that we were on the verge of major discoveries. Thanks to Louis Pasteur, bacteriology had made great strides. We could legitimately hope for a better control of infections. Of course, we were living in an era when the future looked promising and humanity was convinced of its power to dominate every element of its existence. Infectious diseases were being 
increasingly controlled on three fronts, with the development of hygiene, the prevention by immunology (vaccines) and passive immunotherapy (serums), and antibiotic therapy (treatments). Not a year went by without some new and significant breakthrough occurring to bolster our hopes of one day controlling and even eradicating infectious diseases. And at that time I believed it was possible. Certain areas of research were just beginning, and although effective antivirals comparable to antibiotics did not yet exist, it was only a matter of time. We witnessed the retreat of many viral diseases due to improved hygiene practices and the widespread use of vaccines. The time shortened dramatically with each new discovery. It was euphoria, as research had a solution to every problem. And what began as my childhood dream became a personal goal to help contribute to this conquest.

\section{Q. Looking back on your career, what infection control discoveries or milestones were the most important during your period of activity? Which changes were the most signif- icant during your professional career?}

Being of the 'second generation', I was one of those who experienced the genetic 'revolution' and who learned to recognise how biological mechanisms evolved. Watson and Crick's work was only a decade old when I first entered the profession, and the research by Jacob and Monod reinforced the idea we were on the brink of understanding the principles of life. Once attained, we had only to imagine ways to manipulate and direct these principles to fit our needs. But alas, over the years, this increasing optimism was attenuated by the realization that how infectious agents adapted was directly related to how we treated them. In the following years, we watched our once successful antibiotic therapies weaken with the emergence of yet another bacterial resistance mechanism to thwart even the most sophisticated of antibiotics.

At first, our weakened effectiveness was met with relative indifference because we were able to quickly retaliate with each new crisis. Research responded promptly to each new resistance mechanism by introducing a 'new and improved' antibiotic. Scientists were amazed at how these bacteria cleverly adapted themselves at every turn. I too observed with much interest (and quiet trepidation) as mechanisms emerged: strains of synergistine-resistant Staphylococcus, bacteriodes loaded with transmissible plasmids, multiresistant pneumococci, etc. This all occurred in the 70s, at a time when we were convinced that this fight was one from which humanity would ultimately emerge victorious.

Legionella made an abrupt entrance on the scene and was, within a few months, meticulously examined. I personally contributed to the study of a bacterium called Mobiluncus, which had been resisting petri cultivation since the early part of the $20^{\text {th }}$ century.

During the 1980s, a new disease emerged: AIDS. To our amazement, this disease had spread very rapidly in certain sociological areas. Back then, we believed it could be controlled, but soon learned otherwise. The time had come to acknowledge our precariousness, and to realize that each positive action had a downside. Then viral hepatitis emerged and some of the older viruses were identified (hepatitis C, E, etc). Virology had attained the same status as other medical fields of the 80 s.

It was believed that nosocomial infections were not only here to stay, but an acceptable price to pay for the enormous benefits of medical care. Surgical prophylaxis was enormously successful in reducing complications due to infections $-40 \%$ to less than $5 \%$ in procedures involving the digestive tract and pelvis. Despite this, we observed a dramatic increase in the number of multiresistant infections such as methicillinresistant Staphylococcus aureus (MRSA) and enterobacteria that produced extended spectrum beta-lactamases.

Q. In your opinion, which research goals or methods should be optimized in the fight against infectious diseases?

I no longer feel that we will be successful in completely eliminating every infectious disease. Certainly the eradication of measles and the decrease in industrialized countries of poliomyelitis, diphtheria and tuberculosis is encouraging. Nonetheless, we continue to see sporadic flare-ups of infection viewed as forever contained (eg, diphtheria). In addition, increased life expectancy in numerous countries has negatively impacted populations, with increased numbers of persons with a weakened immune system.

Considering today's economically-challenged countries, tangible progress is elusive, as any campaign to eradicate infectious disease proves to be too costly. Unfortunately, given the current organisation of these countries and the hesitancy of their leaders, maximum effectiveness is just not feasible. Consequently, increased research activity and perseverance will produce only meagre results.

In today's world, should we continue to tolerate the transmission of certain viral diseases? With the birth of new epidemics, such as enteroviral meningitis and respiratory syncitial viral bronchiolitis, among others, refusing to take collective action is illogical. Medecine in general, and infectious diseases in particular, react to the isolated individual in an industrialized setting, but fails to consider humanity as a whole. Poor countries, on the other hand, have a more global approach, as they do not have the means to address health issues on an individual basis.

\section{Q. Do you believe that infectious diseases will one day really be eradicated and if so, how can we achieve this goal?}

My professional view is that infectious disease is here to stay! Life is an eternal struggle, and human beings revolve around a balance point. In today's world, this balance is not only unstable but fragile. We live, in part, because of interactions with microorganisms. This then presents a disadvantage in the form of infectious diseases.

The biological cycle includes bacteria for the recycling of matter. The lives of so-called 'superior' living beings (in what way 'superior'?) would be impossible without this interaction. Bacteria have adapted themselves to these superior living beings, and unfortunately, some have negatively affected the fragile balance. The living world is made up of a macroequilibrium that is relatively stable in time and space, yet on an individual level, a certain fragility exists which is more easily disrupted by one or another of these living microorganisms. It is the eternal struggle within the biosphere! So consequently, no, it is inconceivable that we will see the total eradication of the negative effects of bacteria and it is impossible to eliminate pathogenic bacteria.

In addition, human activity provides endless access for infection. New conventional or unconventional transmissible agents are linked to well-known existing pathologies. Take, for instance, the discovery of the connection between certain 
bacteria (Helicobacter pylori and Chlamydia, to name a few) to tumours or degenerative processes such as arteriosclerosis. There is absolutely no doubt in my mind that new infectious agents will emerge in the future, and we will discover that others are associated with diseases which were originally thought to be non-infectious in origin.

Life is constantly evolving... and so are the pathogens.

Merci beaucoup, Monsieur le docteur Dublanchet!

\section{PROFESSOR MARK PALLEN}

$\mathrm{Q}$. What was the situation like in the infectious disease field when you first started out?

It was in a poor state in some ways and in quite a good state in others. Most of the work in medical microbiology (UK medical schools) was fairly 'soft' research, based on pharmaceutical company funding, drug trials, or minimum inhibitory concentrations of new agents against umpteen different clinical isolates. Very little of it was 'hypothesis-driven research'. It was mostly 'service research', instead of building independent research programs. However, there was a lot of research activity in hospital infection control (UK hospitals) which was internationally competitive. But then again, it was not really 'hard' research, it was often just an extension of service development and clinical audit. It really shaded into what people should have really been doing as part of their clinical practice anyway, rather than being fundamental research.

On a more positive note, just as I came into the field, in the mid-1980s, molecular biology - which had been around for about a decade - was starting to flower in the study of bacteria. There were the first research groups starting to work on molecular mechanisms of pathogenesis and starting to develop rational molecular approaches to vaccine development. So there was a feeling that something new and exciting was beginning. However, that activity was, for the most part, going on not in microbiology departments within medical schools, but in other settings. And more importantly, it was often being lead by scientists without a clinical training. I was fortunate that my Head of Department at Barts (Professor Soad Tabaqchali, Saint Bartholomew's Medical School, University of London) recognized this was an important trend and quickly got into molecular biology and started applying it to pathogens, to epidemiological typing, and to the cloning of virulence and antigenic determinants. Her great strength was not so much a mastery of technical details, but her recognition that this was an important field and her ability to recruit smart people to keep the research initiative going. There were very few other environments in the UK like it - many laboratories have, over the years, dabbled in molecular epidemiological typing, done a little PCR [polymerase chain reaction] etc, but very few others have done hypothesis-driven research and recruited external funding from the Wellcome Trust or the Research Councils.

\section{Q. What do you feel have been the most important accomplishments with regard to infectious disease during your period of activity?}

Things have changed quite a lot, but still not enough! That previous generation of professors have retired, but they did not train enough people for the next generation. We now have a crisis of recruitment in academic bacteriology in the UK. It is not perceived as an exciting area to move into, as compared to, say, virology or immunology or cancer studies. Bacteriology is having a crisis, and this has been a subject of an investigation by the British Academy of Medical Sciences. But there have been some good things happening. Gordon Dougan, my $\mathrm{PhD}$ supervisor in the mid-1990s, has had an immense influence on the field of bacterial pathogenesis over the last 15 years. He worked initially at the Wellcome Laboratories in Beckenham on the outskirts of London, where he recruited a group of talented people to work with him. Indeed, many of those he recruited at Beckenham have seeded British universities with nonclinical bacteriologists of the highest calibre.

I was fortunate to participate in a program that allowed people to do three years full-time research at the bench, register for and obtain a $\mathrm{PhD}$, but still be able to plug back into the existing career structure for academic medicine in bacteriology. Several other people have also completed this training. Whether it has been as influential as hoped is open to question. It certainly had a dramatic influence on me, and set my sights and aspirations high. Within two years of obtaining the $\mathrm{PhD}$ and a fellowship, I was awarded a chair in bacteriology and gained three Medical Research Council project grants.

So, bacteriology was transformed by the first wave of innovation with the influence of molecular biology on the subject. The new discipline of molecular pathogenesis followed and the techniques of molecular biology could address problems in detail. Appropriate hypothesis-driven experiments to examine how bacteria cause disease, what makes them tick, how they interact with the host cell, subvert host-cell systems and so forth could be pursued.

This has recently been followed by a second wave of activity flowing from the genomics revolution. We already have over 50 complete bacterial genome sequences, and within a few years we will have the completed genome sequences of every significant bacterial pathogen of humans, plants and animals. This is dramatically changing the field. The hope is that this will provide us with novel reagents for treatments - new classes of antimicrobial drugs that are rationally designed. Rational drug design has already happened in the field of virology, with the neuraminidase inhibitors for influenza. That sort of development could happen with bacteria. There has not yet been a single antibacterial product come out of the genomics revolution, but it takes a long time for this advance to permeate through from genome sequence to clinical trial. Genomics also promises to deliver novel diagnostic approaches and novel vaccines but, again, this takes time.

I do not think there is a critical mass of clinically trained people now. What has been encouraging is that research in bacteriology is now being taken seriously. It is just unfortunate that it has been taken seriously largely by nonclinical people.

Another development in the UK research environment over the last few years has been the Research Assessment Exercise (RAE). Here, every university, school and research group is judged by its research output and peer-reviewed grant income, and an assessment is made of quality. This RAE score then decides how money is distributed centrally to each institution. This process has been applied to medical schools in the same way as to every other university structure, which has meant that in medical schools, nonclinical researchers have achieved a higher profile, particularly in bacteriology. The flip side of this is that the medical positions are under threat. Nonclinical persons cost less in terms for salary and have a better CV. The threat is that there will eventually be nobody doing microbiology research who is medically qualified. There is an 
argument to be made that people with a medical degree will have a broader vision, to be able to look at the bigger picture. They will have seen pathogens in action, killing or maiming patients or spreading from ward to ward, and have questions to address arising out of their clinical experience. So I think that clinical experience matters, but not every microbiology professor in medical schools should be medically qualified. Ideally, we should have a mix of clinical and nonclinical people working effectively together.

\section{Q. What do you foresee as the vital matters that remain to be addressed in countering the problems of infectious disease?}

In the West, the problem of infection has shifted mainly from the community into the hospital environment. Infectious diseases in hospitals will remain a problem, with vulnerable patients for longer periods in intensive care units, and immunosuppressed patients with cancer treatment and transplants. Some of the problems that need to be addressed are not bacterial problems - they are problems of structure and engineering. A lot of hospital infection would disappear if you designed hospitals better, where you had wash basins in the right places and an appropriate number of single rooms where one could isolate patients.

There is certainly a lot of scope for protection of patients who are going into hospitals. We know what the common pathogens are going to be: Clostridium difficile, MRSA, or whatever. We should be able to devise efficient ways of protecting the patients, either with prophylactic antibiotics or passive protection with antibodies, or with active immunization. If everyone who was going to have a triple bypass operation had a vaccine against Staphylococcus aureus, then I am sure we would see less sternal wound infections or septicemias. These are issues that can and should be addressed.

The other area that will be interesting would be to look at the ecology of the infections in hospitals. What is it that causes some strains to become established in hospitals and others to appear once and never be seen again? I think that there are a lot of potential insights that could emerge from genomics. Then maybe we could focus on crucial virulence factors, and target them by inducing a passive immune response, using a monoclonal antibody or some other approach.

Tuberculosis is a prime example of the problems of multidrug resistance. Strains are emerging that are almost impossible to treat with drugs. There is a risk of a postantibiotic apocalypse where organisms that are untreatable will emerge. Our hospitals are already awash with MRSA, which is difficult to treat but not impossible. Vancomycin-resistant enterococci are also extremely difficult to treat. Fortunately, at the moment, vancomycin resistance is confined to organisms that have a fairly low pathogenic potential. If full-blown vancomycin resistance got into MRSA, then we could be effectively back to the preantibiotic era. There are only a couple of ways that we can stop this. The first one is better, more prudent use of antibiotics, and the second is that humans have to outsmart bacteria by developing better agents. I am hopeful that there will be new agents coming out of the genomics revolution. But it will take some years. Also, no one can say why we have not already seen vancomycin resistance in Staphylococcus aureus? There is no physiological or genetic reason that makes it impossible - it has been shown in the laboratory that resistance determinants can be expressed in Staphylococcus aureus.
The other issue in developed countries is communityacquired infection. Sexually transmitted diseases, meningitis, foodborne infections, contamination of the food chain, and so on have not gone away. Infection in the community is not as much a 'killer' as it used to be, but issues still need to be addressed. We still need a vaccine against group B meningococcus. We need to sort out the problem of bacterial contamination of the food chain. Where are those Campylobacters coming from that are causing all this disease? What more can we do to get rid of Salmonella? There have been some developments - for instance, it seems that vaccinating chicks against Salmonella appears to have dampened down the transmission through the food chain, but there is still some way to go. Some of this is a matter of better implementing what we already know in the food industry. But there is still room for basic research in that area say developing unique and efficient vaccines for food animals or changing livestock bacterial ecology so that the organisms do not get a foothold. You could be vaccinating from their food or having some competitive exclusion mechanism where food animals can be given bacterial flora and would not become colonized with Campylobacter.

And diseases in the Third World are absolutely devastating. There is a tremendous need for vaccines and better treatments for malaria and for tuberculosis. There are also problems with gastrointestinal infections in young children, enteropathogenic Escherichia coli, and rotavirus, where cheap, effective interventions would save many lives. Another problem when dealing with control of infection on a worldwide scale is that many useful agents are protected by intellectual property rights and/or cost a lot to manufacture, so the expense is just too high for people in Third World countries. There are some examples where drug companies have acted altruistically, with generosity, for example the donation of ivermectin by Merck to treat and help in the drive to eliminate river blindness in Africa. But these actions are not as common as they ought to be.

So, there are still major problems with infection - some of them might be solved by smart molecular approaches and some of them just require better implementation of current best practice.

\section{Q. Can infectious disease ever practically be eradicated and, if so, how would this be accomplished?}

Much of the burden of infection in hospitals could be lifted if you had the right environment to prevent cross-infection. There are some parts of the world, Scandinavia for example, where MRSA have not so far been a big problem. They have always had the structural components of infection control, eg, good hospital architecture and sufficient funding for enough infection control nurses, and they have had the prudence to enforce antibiotic protocols and so forth. So, I think you could get rid of a great deal, but you could never eradicate infection.

Another way forward would be if some of the 'science fiction' ideas were to come true-if you could grow organs from people by using stem cells. Then you would not have to immunosuppress. Or if you could humanize pig kidneys and educate the patient's immune system to tolerate them, then maybe the need for agents to suppress the entire immune system might disappear. The same would apply if we had other methods to treat cancer that did not require a blunderbuss cytotoxic approach which kills all the replicating cells, including those in the gastrointestinal tract and the immune system. And similarly, if we 
had efficient ways to make tissue grow quickly and repair itself, then some of the window of vulnerability to infection would disappear following injuries. Much of this is not really within the sphere of infectious diseases, but rather the practices of oncology, tissue engineering and so forth.

In the community, there are still many infections that could theoretically be eradicated. Where there is an infection with only human-to-human spread, with no animal or environmental reservoir, then this could be amenable to eradication. Polio, they say, is close to eradication. Diphtheria is another example of a human disease where there is no animal reservoir. There are many examples of other diseases for eradication. Examples include HIV, shigellosis and tuberculosis, where human-tohuman spread is paramount, even if animal reservoirs exist.

Opportunistic pathogens, where human infection is an incidental side effect of their normal lifestyle and ecology, will be impossible to eradicate, eg, Clostridium tetani or Legionella pneumophila. You can eliminate tetanus in every generation by vaccinating everyone, but then you would never get to the stage where you could stop vaccinating people, as we have with smallpox and soon will with polio. So you could never entirely eliminate the threat of infectious diseases even though much could be done to neutralize it. And there are always new threats coming in, with changes in lifestyle and in ecology and geography, eg, West Nile virus in the USA.

But if you step back a little and take a historical view - if you take what has happened in Western society in the last hundred years - then, thanks to the engineers and microbiologists and pharmaceutical companies and public health people, we have already, to the first approximation, eradicated infection as a major player in our societies. Yes, when you consider the difference, ie, the difference in the infant mortality rates, in childhood deaths from diphtheria and diarrheal diseases, from tuberculosis and scarlet fever between our time and, say, Charles Darwin's (who lost a precious daughter to infection), we have gotten rid of all that, largely. From being one of the commonest causes of childhood death, the number of cases of diphtheria in the UK has gone down to one or two a year...

Thank you very much, indeed, Professor Pallen.

ACKNOWLEDGEMENTS: MG wishes to thank Monsieur Jean-Philippe Emond of the Centre Hospitalier Intercommunal de Villeneuve-Saint-Georges, Villeneuve-Saint-Georges, France and Madame Claire Kingston at the Faculté des Sciences de l'Education, Université Laval, Quebec, Canada for their cultural support. He is indebted to the Staff of the Wellcome Unit for the History of Medicine at Oxford for their kindness, attention and constant cooperation.

NOTE: While the specialists involved are located in the United Kingdom and France, which have traditionally been great sources of knowledge in matters of infection, there should be a direct applicability for the Canadian scene.

For those interested, the contact address of each of the three interviewees are:

Professor Brian Lacey, 19 Saint John's Hill, Shrewsbury, SY1 1JJ, United Kingdom

Docteur Alain Dublanchet, Laboratoire de Microbiologie et Virologie, Centre Hospitalier Intercommunal de Villeneuve-Saint-Georges, 40, Allée de la Source, Villeneuve-Saint-Georges Cédex 94195, France

Professor Mark Pallen, Division of Immunity and Infection, School of Medicine, University of Birmingham, Birmingham, B15 2TT, United Kingdom 


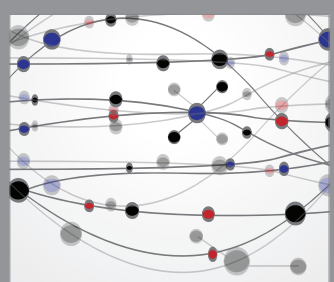

The Scientific World Journal
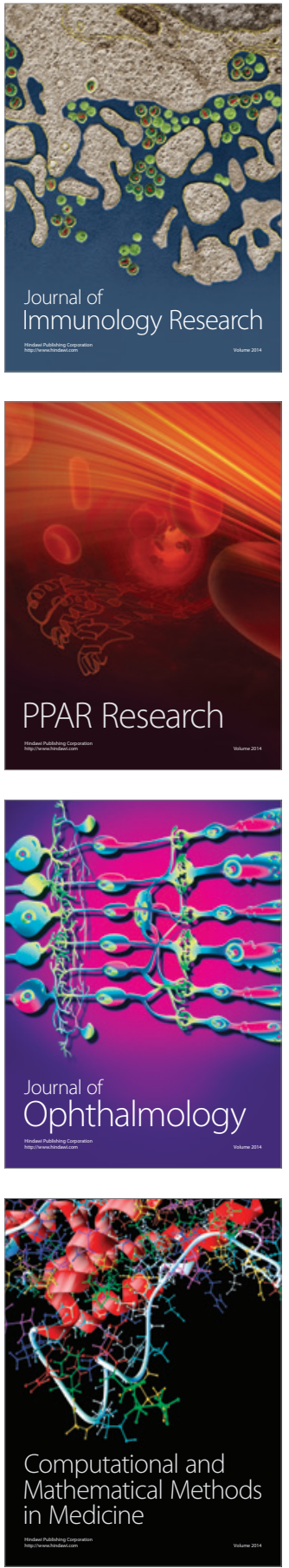

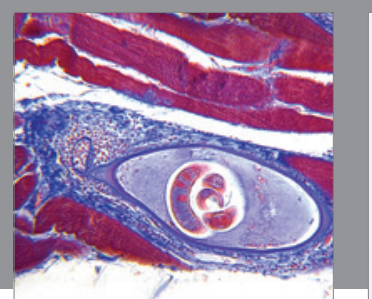

Gastroenterology Research and Practice

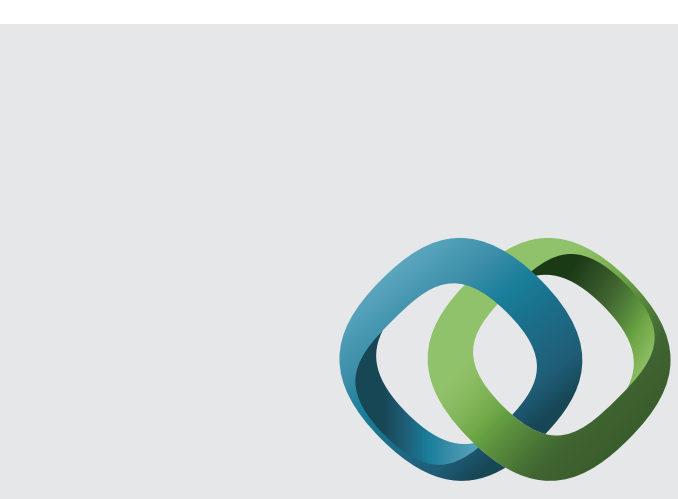

\section{Hindawi}

Submit your manuscripts at

http://www.hindawi.com
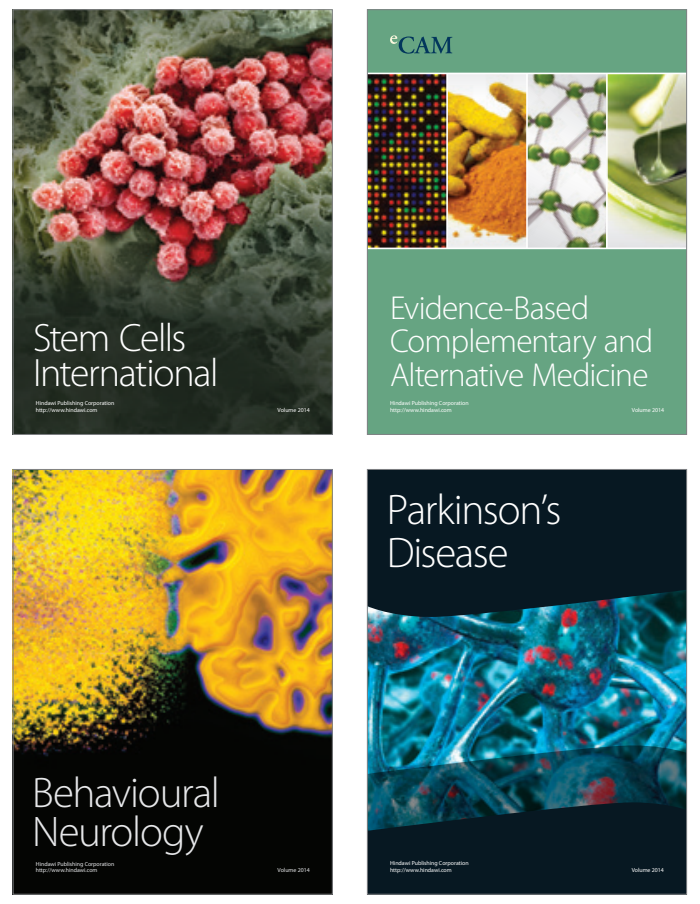
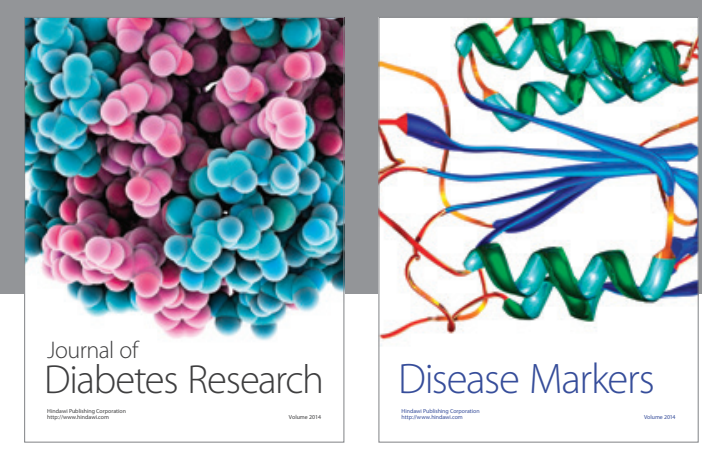

Disease Markers
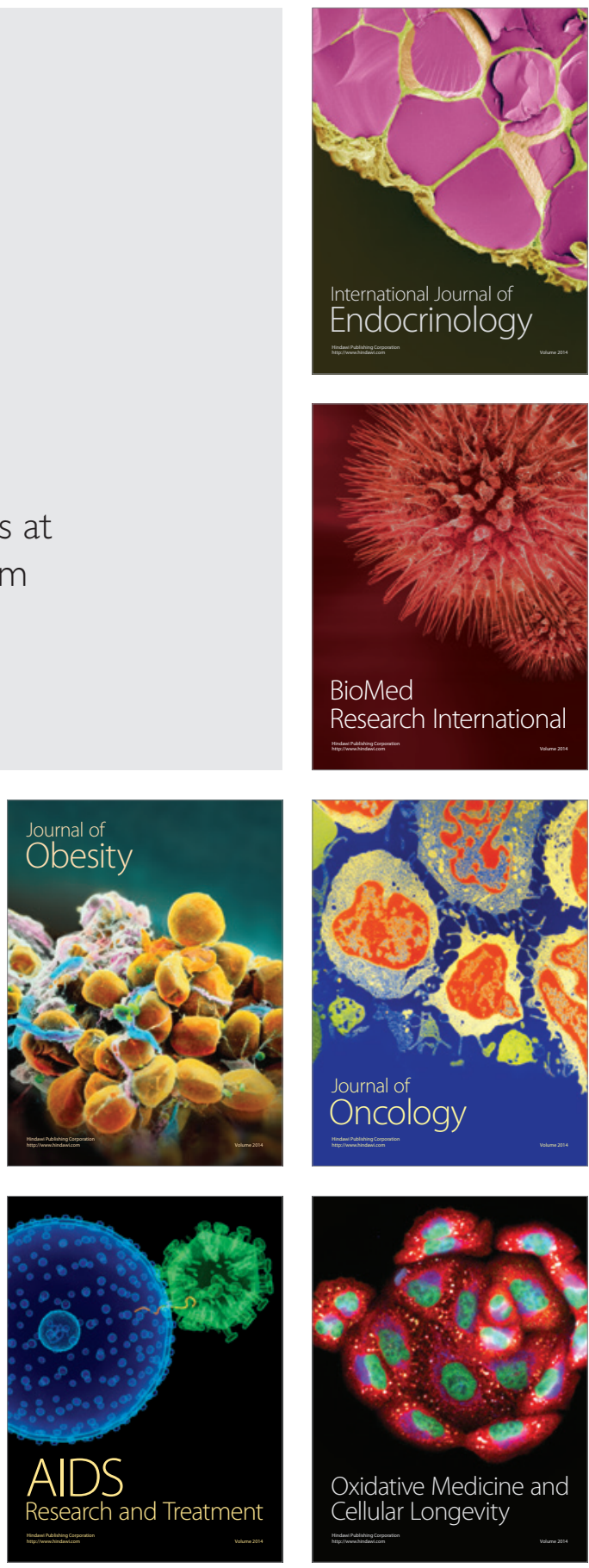